\title{
Estudo dos Cortes da Carcaça de Cordeiros Santa Inês Puros e Cruzas Santa Inês com Texel, Ile de France e Bergamácia ${ }^{1}$
}

\author{
Iraides Ferreira Furusho-Garcia², Juan Ramón O. Perez ${ }^{3}$, Sarita Bonagurio ${ }^{4}$, Alisson Luís Lima ${ }^{5}$, \\ Fábio Arantes Quintão5
}

\begin{abstract}
RESUMO - Foram utilizados 103 cordeiros, machos e fêmeas, Santa Inês puros (SS) e cruzas Santa Inês com Texel (TS), Ile de France (FS) e Bergamácia (BS), confinados em gaiolas individuais. Os cordeiros foram abatidos em quatro pesos: 15,0; 25,0; 35,0 e 45,0 kg de peso vivo. Após o abate e resfriamento da carcaça, foram feitos os seguintes cortes e calculadas as porcentagens em relação ao peso da carcaça fria: pescoço (PP), costela/fralda (PCF), costeleta (PC), lombo (PL), paleta (PPA) e perna (PPE), sendo esses dois últimos sem os braços. Os pescoços praticamente não variaram com o aumento dos pesos de abate. Os pescoços dos cordeiros TS e FS foram menores, comparados aos dos cordeiros SS e BS, na maioria dos pesos de abate estudados. A paleta também não variou com o aumento dos pesos de abate, havendo tendência para diminuição. Aos 45 kg, os cordeiros TS e FS apresentaram PPA maiores em relação aos cordeiros SS e BS. Nos outros pesos de abate, praticamente não houve diferenças para PPA entre os grupos genéticos. A costela/fralda elevou-se com o aumento dos pesos de abate, sendo que, em pesos de abate elevados, os cordeiros TS mostraram maiores proporções. Para a PC, praticamente não houve diferenças entre os pesos de abate. As fêmeas FS, entretanto, aos 35 e $45 \mathrm{~kg}$, apresentaram menores PCF que os machos FS. O lombo tendeu a elevar-se com o aumento dos pesos de abate, mas foram detectadas diferenças para os animais abatidos aos $15 \mathrm{~kg}$, em relação aos outros pesos de abate. Entre os grupos genéticos, praticamente não houve diferenças para PL. As pernas diminuíram com o aumento dos pesos de abate. Aos $35 \mathrm{~kg}$ de peso vivo, os cordeiros machos TS e as fêmeas FS obtiveram melhores PPE em relação aos outros grupos genéticos.
\end{abstract}

Palavras-chave: carne ovina, cruzamento, ovinos, peso de abate

\section{Study of the Carcass Cuts of Santa Inês and Crosses with Texel, Ile de France and Bergamacia Lambs}

\begin{abstract}
One hundred and tree male and female lambs, pure Santa Inês (SS) and crosses between Santa Inês and Texel (TS), Ile de France (FS) and Bergamacia (BS), were used. They were confined in individual cages. The lambs were slaughtered at four weights: 15.0, 25.0, 35.0 and $45.0 \mathrm{~kg}$ live weight. After slaughter and cooling of the carcasses, the following cuts were made: neck (PP), rib/flank (PCF), rack (PC), loin (PL), shoulder (PPA) and leg (PPE), these last two without the arms. Necks practically did not vary with the increase of slaughter weights. Necks of TS and FS lambs were smaller, compared to the SS and BS lambs, in most of the studied slaughter weights. Shoulders also did not vary with the increase of slaughter weights with a tendency to decrease. At $45 \mathrm{~kg}$, TS and FS lambs presented greater PPA in relation to SS and BS lambs. In other slaughter weights, pratically there were no considerable PPA differences between the genetic groups. Rib/flanks increased with the increase of slaughter weights, and, in higher slaughter weights, the TS lambs showed greater proportions. For CP, there was practically no difference among slaughter weights. Ile de France females, however, at 35 and $45 \mathrm{~kg}$, showed PCF smaller than FS males. Loins tended to increase with the increase of slaughter weights, but differences were detected in the animals slaughtered at $15.0 \mathrm{~kg}$, in relation to the other slaughter weights. Among the genetic groups there was no difference for the PL. Legs decreased with the increase of slaughter weights. At $35 \mathrm{~kg}$ live weight, the male TS and the female FS lambs obtained better PPE in relation to the other genetic groups.
\end{abstract}

Key Words: sheeps, crossbreding, sheep meat, slaughter weight

\section{Introdução}

No Brasil, a necessidade de produzir carne ovina de qualidade é notória. Registra-se baixo consumo da carne ovina, o que está relacionado, primeiramente, com a baixa oferta e, depois, com a baixa qualidade do produto colocado à venda. A falta de fornecimento de carcaças de animais jovens que apresentem boas características e de cortes para facilitar o preparo da carne é um dos principais fatores que prejudicam o

\footnotetext{
1 Parte da tese de Doutorado do primeiro autor. Projeto financiado pela FAPEMIG

2 Profa Adj. - DZO - Faculdade de Ciências Agrárias - Faculdades Federais Integradas de Diamantina - FAFEID (ifurusho@fafeod.br)

3 Prof. Titular do DZO - UFLA (jroperez@ufla.br).

4 Doutoranda em Zootecnia - Unesp/Botucatu (sasabona@laser.com.br).

5 Aluno do curso de graduação - ULFA.
} 
crescimento do consumo e a sua comercialização.

A padronização dos cortes a serem comercializados é definida pelo mercado consumidor, que determina pesos mínimos e máximos de acordo com os costumes regionais. Um corte ideal é aquele de fácil utilização na culinária e que não tenha excesso nem falta de gordura. O ótimo peso para cada corte será aquele em que a sua valorização é máxima, tanto para o produtor como para o consumidor. Distintos cortes possuem valores econômicos diferentes, e a proporção de cada um é importante na avaliação da qualidade comercial da carcaça (Huidobro \& Cañeque, 1993).

No Brasil, poucas são as pesquisas que visam à avaliação de cortes da carcaça de cordeiros e os efeitos que diversos fatores podem ter sobre os mesmos. Entre esses fatores estão o peso de abate associado com a genética, a qual deve ser direcionada para obtenção de animais resistentes e produtivos.

De acordo com Santos \& Pérez (2000), o sistema de cortes deve respeitar aspectos como quantidades relativas de músculo, gordura e osso; facilidade de realização pelo operador; e versatilidade, ou seja, facilidade de uso pelo consumidor.

O rendimento dos cortes da carcaça é um dos principais fatores que estão diretamente relacionados com a qualidade da carcaça (Sainz, 1996). Conforme Colomber-Rocher et al. (1988), o rendimento de carcaça é determinado pelos diversos componentes corporais do animal, e o valor de uma carcaça depende, entre outros fatores, dos pesos relativos de seus cortes, sendo que, para melhorar esse valor, torna-se necessário aprimorar aspectos relativos à nutrição, sanidade, manejo, raças e cruzamentos.

Segundo Boccard (1965), Sierra (1974), Sañudo (1980) e Lopez (1987), citados por Osório et al. (1995); Oliveira et al. (1998); e Silva et al. (2000), pode-se esperar que a proporção dos cortes seja influenciada por raça, sexo, peso de abate e sistema de criação. A raça é citada por Rohr \& Daenicke (1984) e Osório et al. (1995) como um fator importante que afeta a distribuição dos pesos relativos dos diferentes cortes da carcaça. Existem variações positivas e negativas na proporção de cortes, com o aumento do peso de abate (Silva \& Portugal, 2000).

Ao comparar grupos genéticos diferentes, a proporção dos cortes da carcaça pode ser diferente em função dos diferentes estádios de maturidade (Perry \& Arthur, 2000). De acordo com Huidobro \& Cañeque (1993), animais da raça Manchega, abatidos aos $15 \mathrm{~kg}$, apresentaram maiores proporções de perna e paleta e menores proporções de costela, quando abatidos aos $35 \mathrm{~kg}$.

Os principais cortes que podem ser obtidos em ovinos são: perna, lombo, paleta, costela, costela descoberta e baixos (Colomer-Rocher et al., 1972). A perna corresponde às regiões anatômicas sacrais e glútea femural; o lombo tem como base óssea as vértebras lombares; a paleta é formada pela escápula, úmero, rádio, cúbito e ossos do carpo; a costela ou costeleta, pela última vértebra cervical e pelas vértebras dorsais; e os baixos ou costela/fralda, pela parede abdominal e metade ventral torácica. Segundo Santos (1999), a perna e a paleta, respectivamente, podem ser classificadas como cortes de primeira e segunda.

Este trabalho foi conduzido objetivando-se a avaliação dos cortes da carcaça de cordeiros, machos e fêmeas, Santa Inês puros e cruzas com as raças Texel, Ile de France e Bergamácia, abatidos em diferentes pesos.

\section{Material e Métodos}

O experimento foi conduzido no Setor de Ovinocultura do Departamento de Zootecnia da Universidade Federal de Lavras.

Foram utilizados 103 cordeiros, machos e fêmeas, provenientes de acasalamentos entre ovelhas da raça Santa Inês e reprodutores das raças Santa Inês (SS), Texel (TS), Ile de France (FS) e Bergamácia (BS). Todos os cordeiros nasceram no período de junho a julho de 1999.

Os cordeiros foram confinados individualmente, até atingirem $14 \mathrm{~kg}$ de peso vivo, em gaiolas com 1,3 $\mathrm{m}^{2}$ de área, contendo cochos e bebedouros separados.

A dieta fornecida (Tabela 1) durante todo o período experimental foi balanceada de acordo com as exigências do ARC (1980) para ganho de 300 g/dia, composta de $80 \%$ de concentrado e $20 \%$ de feno de coastcross (Cynodon dactylon) moído. Os animais receberam alimentação à vontade.

Foram considerados quatro pesos de abate: 15, 25, 35 e $45 \mathrm{~kg}$. Os animais de cada grupo genético e de cada sexo foram distribuídos aleatoriamente dentro de cada peso de abate. Os cordeiros abatidos aos $15 \mathrm{~kg}$ não passaram pelo confinamento após o desmame, permanecendo em grupo até atingirem o peso de abate.

Antes do abate, os animais passaram por um período de jejum de aproximadamente 16 horas, tendo acesso somente à água.

\section{R. Bras. Zootec., v.33, n.2, p.453-462, 2004}


No abate, os animais foram suspensos pelos membros posteriores e atordoados. Posteriormente, procedeu-se a um corte na artéria carótida e nas veias jugulares. O sangue e a pele foram coletados e pesados. Em seguida, retiraram-se todas as vísceras, cujos conteúdos foram pesados e descontados para determinação do peso corporal vazio (PCV).

Após o abate e evisceração, foi tomado o peso da carcaça quente (CQ). Essa carcaça permaneceu por um período de 24 horas em câmara fria $\left(2 \mathrm{a} 4^{\circ} \mathrm{C}\right)$; em seguida, foi novamente pesada, obtendo-se o peso da carcaça fria $(\mathrm{CF})$. Foram retirados o pescoço, a cauda, os rins e as gorduras renais, pélvica e inguinal e, então, a carcaça foi dividida longitudinalmente em duas metades.

A metade esquerda da carcaça foi subdividida nos seguintes cortes: perna, lombo, paleta, costeleta, costela/fralda, braço anterior e braço posterior, de acordo com a Figura 1. Esses cortes foram pesados e, então, calculou-se a porcentagem de cada um em relação ao peso da carcaça fria.

A obtenção de cada corte obedeceu às seguintes definições:

A perna correspondeu à região sacral, contendo o cíngulo pélvico. O corte foi realizado na altura da

Tabela 1 - Composição percentual (\%) de ingredientes da dieta

Table 1 - Composition of the experimental diet (\%)

\begin{tabular}{|c|c|}
\hline $\begin{array}{l}\text { Ingredientes } \\
\text { Ingredient }\end{array}$ & $\begin{array}{c}\% \text { na matéria natural } \\
\% \text { as fed }\end{array}$ \\
\hline Feno de coastcross & 20,00 \\
\hline Coastcross hay & \\
\hline Milho moído & 66,45 \\
\hline Corn ground & \\
\hline Farelo de soja & 12,40 \\
\hline $\begin{array}{l}\text { Soybean meal } \\
\text { Calcário }\end{array}$ & 0,85 \\
\hline $\begin{array}{l}\text { Limestone } \\
\text { Sal comum }\end{array}$ & 0,25 \\
\hline Salt & 0,01 \\
\hline $\begin{array}{l}\text { Mineral supplement } \\
\text { Suplemento vitamínico } 2 \\
\text { Vitamin supplement }\end{array}$ & 0,04 \\
\hline TOTAL & 100,00 \\
\hline \multicolumn{2}{|c|}{$\begin{array}{l}1 \text { (nutriente } / \mathrm{kg} \text { de suplemento): Selênio }=150 \mathrm{mg} \text {, lodo }=1.000 \mathrm{mg} \text {, } \\
\text { Cobalto }=600 \mathrm{mg} \text {, Ferro }=35.000 \mathrm{mg} \text {, Cobre }=20.000 \mathrm{mg} \text {, } \\
\text { Manganês }=49.000 \mathrm{mg} \text {, Zinco }=75.000 \mathrm{mg} ; \\
2 \text { (nutriente } / \mathrm{kg} \text { de suplemento): Vitamina A }=2.500 .000 \mathrm{UI} \text {, Vita- } \\
\text { mina D3 } 500.000 \mathrm{Ul} \text {, Vitamina E } 3.000 \mathrm{mg} \text {, Tiamina }=750 \mathrm{mg} \text {, } \\
\text { Riboflavina }=1.000 \mathrm{mcg} \text {, Vitamina B12 }=2.800 \mathrm{mg} \text {, Niacina }=500 \\
\text { mg. }\end{array}$} \\
\hline
\end{tabular}

R. Bras. Zootec., v.33, n.2, p.453-462, 2004 última vértebra lombar e primeira sacral e na articulação da tíbia com o fêmur, ou seja, o braço posterior, que contém o osso da tíbia, não fez parte desse corte.

O lombo tem a sua base óssea desde a primeira até a última vértebra lombar. Um dos cortes foi feito entre a última vértebra torácica e a primeira lombar, e o outro, entre a última lombar e a primeira sacral.

O carrê ou costeleta é a região entre a $1^{\mathrm{a}}$ e a $13^{\mathrm{a}}$ vértebra torácica, juntamente com $1 / 3$ do corpo das costelas correspondentes.

$\mathrm{O}$ peito/fralda ou costela/fralda corresponde à região anatômica da parede abdominal e $2 / 3$ da região ventral torácica. A base óssea corresponde ao esterno cortado sagitalmente, a 2/3 ventrais das oito primeiras costelas e ao terço ventral das cinco restantes. O corte foi realizado paralelamente à coluna vertebral, partindo desde a prega inguinal e terminando no cordão testicular.

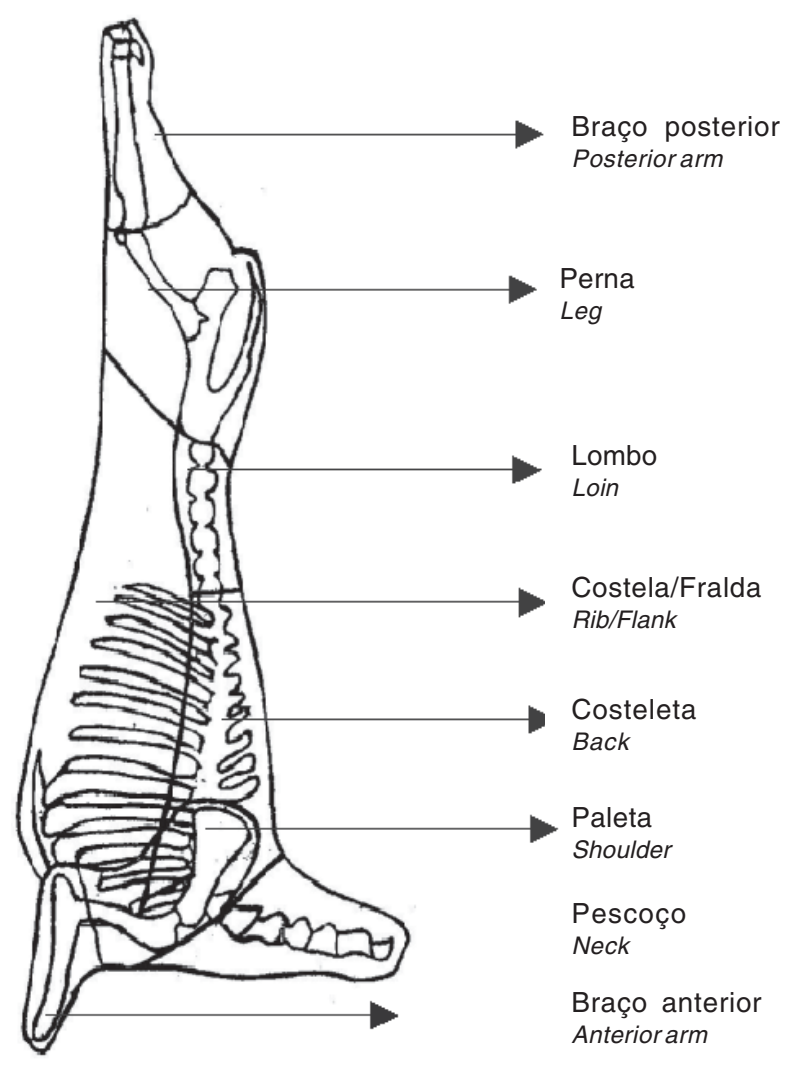

Figura 1 - Cortes efetuados na meia carcaça esquerda. (Sistema de cortes adotado pela Universidade Federal de Lavras).

Figure 1 - Cuts were performed in the half left carcass (Cuts system adopted by Federal University of Lavras). 
A paleta corresponde às regiões anatômicas do cíngulo escapular, braço e antebraço, sendo a base óssea formada pela escápula, úmero, rádio e ossos do carpo. $\mathrm{O}$ corte foi feito na região axilar dos músculos que unem a escápula e o úmero na parte ventral do tórax.

Para a análise estatística dos dados, foi considerado um delineamento inteiramente casualizado (DIC), com diferentes repetições, nos 32 tratamentos obtidos em um esquema fatorial $4 \times 4 \times 2$ (quatro grupos genéticos, quatro pesos de abate e dois sexos), sendo distribuídos aleatoriamente de 3 a 5 animais para cada um; portanto, um experimento desbalanceado.

Os dados foram analisados com o uso do programa (SAS, 1999). As médias ajustadas foram comparadas duas a duas, de acordo com teste t, para peso de abate, de cada sexo, dentro de cada grupo genético; grupo genético, de cada sexo, dentro de cada peso de abate; e sexo, de cada grupo genético, dentro de cada peso de abate. Todos as fontes de variação foram estudadas separadamente em função dos objetivos do trabalho, ou seja, como se as interações triplas fossem significativas.

Procedeu-se também à análise de regressão, pelo procedimento REG do SAS (SAS, 1999), para avaliação do efeito dos quatro diferentes pesos. Foram testados os modelos linear, quadrático e cúbico.

\section{Resultados e Discussão}

Os dados médios de porcentagem do pescoço em relação à carcaça fria são mostrados na Tabela 2.

A porcentagem do pescoço, aos $45 \mathrm{~kg}$ de peso vivo, das cordeiras TS foi maior $(\mathrm{P}<0,05)$ que a dos machos TS, o que pode ser explicado pela maior deposição de gordura das fêmeas desse grupo genético, que são mais precoces. Não ocorreram diferenças $(P>0,05)$ entre os sexos para os outros grupos genéticos, em nenhum dos pesos de abate.

Para o abate aos $15 \mathrm{~kg}$, as cordeiras SS apresentaram percentual maior $(\mathrm{P}<0,05)$ do pescoço, comparado ao das fêmeas dos outros grupos; aos $25 \mathrm{~kg}$, os machos dos grupos BS apresentaram maior $(\mathrm{P}<0,05)$ porcentagem de pescoço que os dos grupos TS e FS.

Aos $35 \mathrm{~kg}$, a porcentagem do pescoço foi menor $(\mathrm{P}<0,05)$ para as fêmeas dos grupos TS e FS. Já aos $45 \mathrm{~kg}$, as fêmeas FS igualaram-se $(\mathrm{P}<0,05)$ às porcentagens apresentadas pelas cordeiras SS e BS.

Aos 35 e $45 \mathrm{~kg}$ de peso vivo, os cordeiros machos TS apresentaram menores porcentagens de pescoço que os cordeiros BS, sendo que, para o abate aos $35 \mathrm{~kg}$,

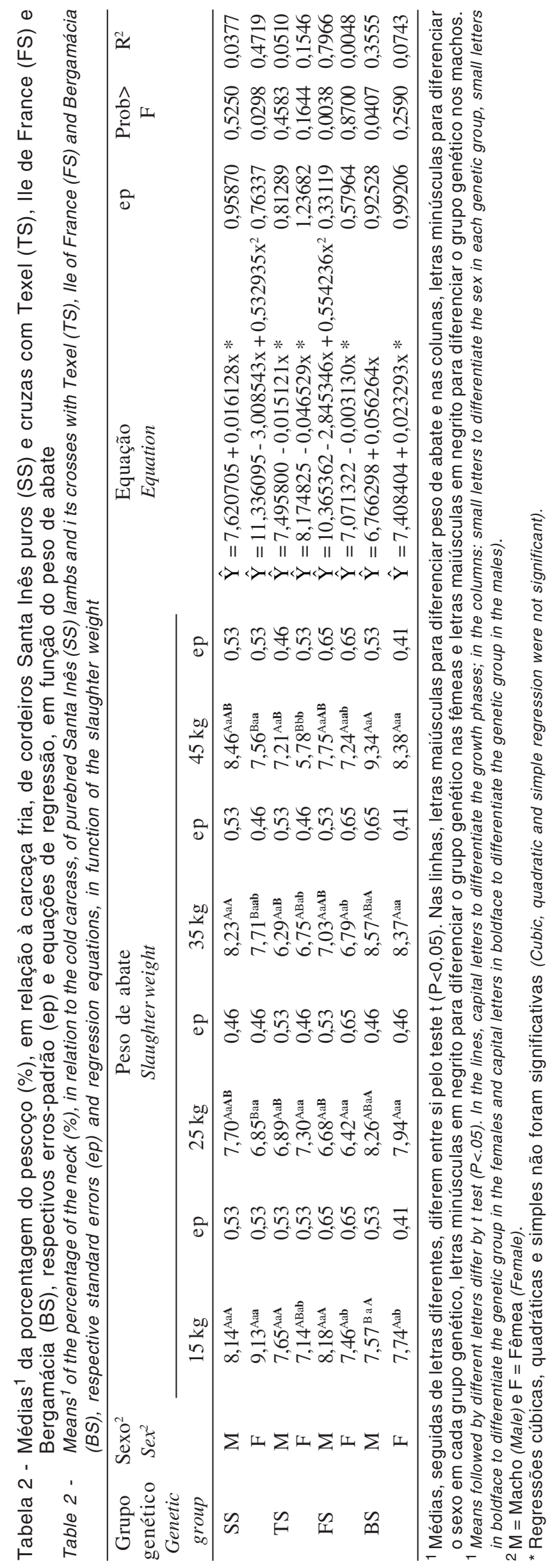


os TS diferiram também dos cordeiros SS $(\mathrm{P}<0,05)$. De acordo com esses dados, os cordeiros SS e BS possuem maior porcentagem para esse corte, em função do seu maior porte, o que é uma característica das raças Santa Inês e Bergamácia, comparadas às outras duas raças paternas usadas nos cruzamentos.

$\mathrm{O}$ valor médio para porcentagem de pescoço para os machos TS, considerando os quatro pesos de abate, foi 7,0\%, superior ao observado por Silva et al. (2000), que foi de 4,5\% para cordeiros Texel x Ideal, abatidos aos 25,48 kg de peso vivo, e semelhante ao valor citado por Oliveira et al. (1998), de 6,90\%, para cordeiros Texel com 12,27 kg de peso de carcaça.

Comparando as médias entre os pesos de abate, notou-se que as fêmeas SS apresentaram menor proporção de pescoço aos 25,35 e $45 \mathrm{~kg}$, comparadas às abatidas aos $15 \mathrm{~kg}$. As fêmeas TS apresentaram maior $(\mathrm{P}<0,05)$ proporção de pescoço aos $25 \mathrm{~kg}$, comparadas àquelas abatidas aos $45 \mathrm{~kg}$. Os machos do grupo genético BS apresentaram maior $(\mathrm{P}<0,05)$ proporção aos 25 e $45 \mathrm{~kg}$ em relação aos abatidos aos $15 \mathrm{~kg}$. Para os grupos genéticos SS e FS, não houve diferença $(P>0,05)$ para a característica em questão entre os pesos de abate.

Os dados da análise de regressão mostraram que a proporção do pescoço foi praticamente constante, independentemente do aumento do peso de abate, exceto para os machos BS, para os quais se observa coeficiente de regressão significativo $(\mathrm{P}<0,05)$, mostrando que esses animais tiveram aumento linear da proporção de pescoço, à medida que se aumentou o peso de abate. Para as fêmeas SS e os machos FS, o modelo de regressão que melhor se ajustou foi o quadrático, com $\mathrm{R}^{2}$ iguais a 0,47 e 0,80 , respectivamente. Observou-se, para esses animais, que a proporção do pescoço foi maior em pesos menores de abate, diminuiu em pesos intermediários e aumentou novamente em pesos de abate mais elevados.

$\mathrm{Na}$ Tabela 3, são mostrados os valores médios para a porcentagem da paleta em relação ao peso da carcaça fria.

A única diferença observada entre os machos e as fêmeas foi no grupo SS, para os animais abatidos aos $45 \mathrm{~kg}$ de peso vivo, no qual as fêmeas mostraram maior porcentagem de paleta $(\mathrm{P}<0,05)$ em relação à carcaça fria, em contraposição aos resultados obtidos por Silva et al. (2000), os quais obtiveram, em machos, maior porcentagem de paleta que em fêmeas.

Com relação à comparação dos grupos genéticos dentro dos pesos de abate, os machos SS, abatidos aos $15 \mathrm{~kg}$, apresentaram menor porcentagem de paleta que os cordeiros TS e BS abatidos no mesmo peso $(\mathrm{P}<0,05)$. Para os animais abatidos aos 25 e $35 \mathrm{~kg}$, não houve diferenças para a porcentagem da paleta ( $\mathrm{P}>0,05)$. Já para os abatidos aos $45 \mathrm{~kg}$, os machos TS e FS apresentaram maior porcentagem que os animais SS; as fêmeas SS mostraram porcentagens maiores que as cordeiras FS e BS, e as fêmeas TS apresentaram porcentagem maior que as cordeiras BS $(\mathrm{P}<0,05)$.

O valor médio para porcentagem, considerando as duas paletas da carcaça, foi de: 14,2; 15,32 e 15,3, respectivamente, para os machos SS, TS e FS, os quais foram inferiores aos observados por Oliveira et al. (1998) e Silva et al. (2000), que obtiveram, respectivamente, valores de $19,14 \%$ para cordeiros Texel x Ideal e 20,23\% para cordeiros Texel.

A porcentagem da paleta dos machos BS foi menor para os animais abatidos aos $15 \mathrm{~kg}$, comparada à daqueles abatidos aos $45 \mathrm{~kg}(\mathrm{P}<0,05)$. Para os demais grupos genéticos, não se observou diferença $(\mathrm{P}<0,05)$. Para fêmeas, os grupos genéticos SS e TS apresentaram menor porcentagem da paleta aos $35 \mathrm{~kg}$, não diferindo, porém, da encontrada para o peso de abate aos $25 \mathrm{~kg}$; no caso das SS, também não houve diferença para as cordeiras abatidas aos $15 \mathrm{~kg}$. Para os outros grupos, não houve variação da porcentagem da paleta, com o aumento do peso de abate. Resultados diferentes foram relatados por Huidobro \& Cañeque (1993), que verificaram diferenças entre os animais abatidos aos $15 \mathrm{~kg}$ e os abatidos aos 25 e $35 \mathrm{~kg}$. De acordo com Lohose et al. (1971), a paleta, por ter desenvolvimento precoce, pode ter redução nas porcentagens com aumento de peso; entretanto, para a maioria dos animais deste experimento, isso não ocorreu.

Os valores médios para porcentagem da costela/ fralda em relação à carcaça fria são mostrados na Tabela 4.

As porcentagens da costela/fralda, aos $25 \mathrm{~kg}$, das fêmeas TS e BS foram maiores $(\mathrm{P}<0,05)$ do que as dos machos dos mesmos grupos genéticos. Aos $45 \mathrm{~kg}$, as cordeiras FS tiveram maior proporção de costela/ fralda que os machos $(\mathrm{P}<0,05)$. Neste peso, os machos SS tiveram maior porcentagem que as fêmeas $(\mathrm{P}<0,05)$.

Os animais abatidos aos 15 e $25 \mathrm{~kg}$ não mostraram diferenças $(\mathrm{P}<0,05)$ entre os grupos genéticos para a porcentagem da costela/fralda. No peso de abate de $35 \mathrm{~kg}$, as fêmeas TS apresentaram porcentagem superior $(\mathrm{P}<0,05)$, comparadas às cordeiras do grupo BS.

\section{R. Bras. Zootec., v.33, n.2, p.453-462, 2004}




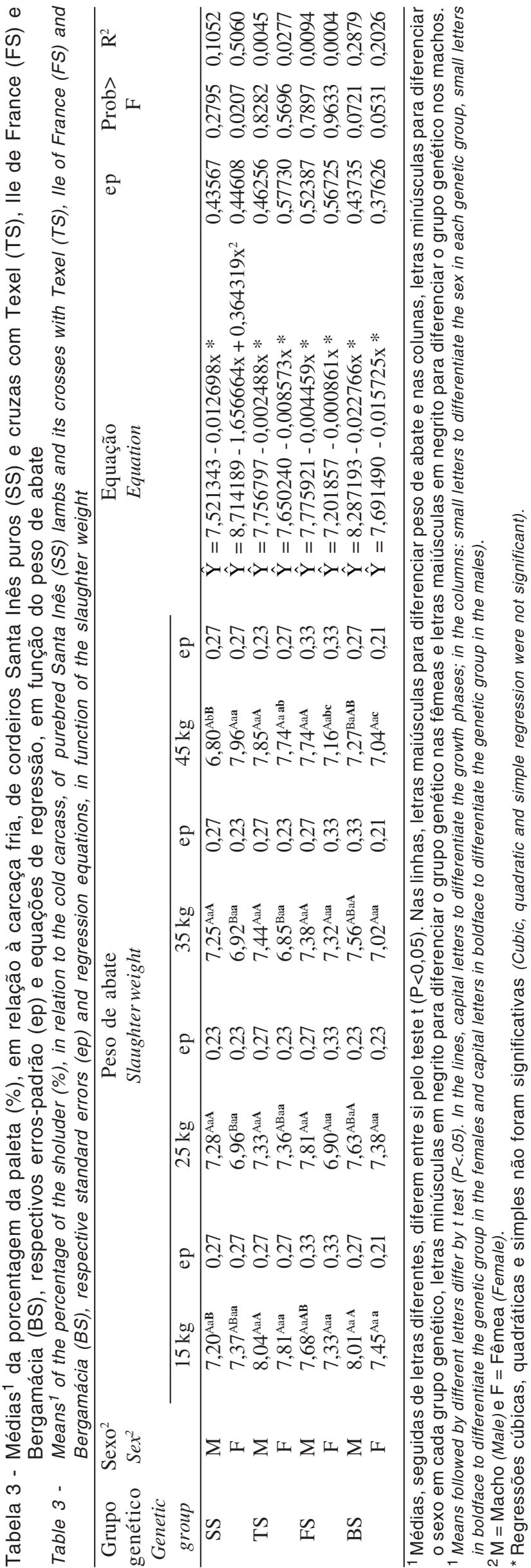

Aos $45 \mathrm{~kg}$, os machos TS mostraram maior $(\mathrm{P}<0,05)$ porcentagem do corte que os grupos FS e BS. Para as fêmeas, as cordeiras SS apresentaram porcentagens maiores $(\mathrm{P}<0,05)$ que os outros grupos.

Para a maioria dos grupos genéticos, ocorreram aumentos da porcentagem da costela/fralda, com o aumento do peso do animal, como pode ser observado pelos dados dos coeficientes de regressão significativos, indicando aumento de forma linear da proporção. Exceções ocorreram para as fêmeas SS e machos FS, para os quais nenhum dos modelos testados, linear, quadrático e cúbico, foi significativo. De acordo com algumas pesquisas (Lohose et al., 1971; Santos, 1999; Silva \& Portugal, 2000), a costela/fralda, como faz parte de uma região que se desenvolve mais tardiamente, apresenta incrementos na porcentagem com o aumento do peso do animal.

Os dados para a porcentagem da costeleta em relação à carcaça fria são mostrados na Tabela 5 .

As diferenças entre sexos foram observadas para o grupo genético $\mathrm{FS}$ aos 35 e $45 \mathrm{~kg}$ de peso vivo, tendo os machos apresentado valores maiores para porcentagem da costeleta $(\mathrm{P}<0,05)$.

Aos $15 \mathrm{~kg}$, os machos não apresentaram diferenças $(\mathrm{P}<0,05)$ entre os grupos genéticos na proporção da costeleta. Já para as fêmeas, a porcentagem foi maior $(\mathrm{P}<0,05)$ para as cordeiras FS, em comparação com as fêmeas SS e BS.

Aos $25 \mathrm{~kg}$, os machos do grupo FS apresentaram maior $(\mathrm{P}<0,05)$ proporção em comparação com os grupos SS e BS. Neste mesmo peso, a proporção da costeleta para os machos TS foi maior $(\mathrm{P}<0,05)$ que a apresentada pelos animais BS. A porcentagem da costeleta para as cordeiras FS foi maior $(\mathrm{P}<0,05)$ que para as cordeiras TS.

Aos $35 \mathrm{~kg}$ de peso vivo, as cordeiras FS, que até então vinham apresentando valor maior de costeleta, passaram a ter porcentagem menor $(\mathrm{P}<0,05) \mathrm{em}$ relação às cordeiras do grupo BS. Neste peso, os machos SS tiveram porcentagens maiores $(\mathrm{P}<0,05)$ que os cordeiros BS.

Com $45 \mathrm{~kg}$, tanto os machos quanto as fêmeas não apresentaram diferenças $(\mathrm{P}<0,05)$ entre os grupos genéticos para a variável em questão.

Os machos SS, FS e BS e as fêmeas SS tiveram valores menores $(\mathrm{P}<0,05)$ nos pesos iniciais, comparados aos valores obtidos pelos animais abatidos aos $45 \mathrm{~kg}$. Aumentos na região costilhar, à medida que o peso de abate se eleva, também foram observados por Bueno et al. (2000). Os cordeiros machos e 


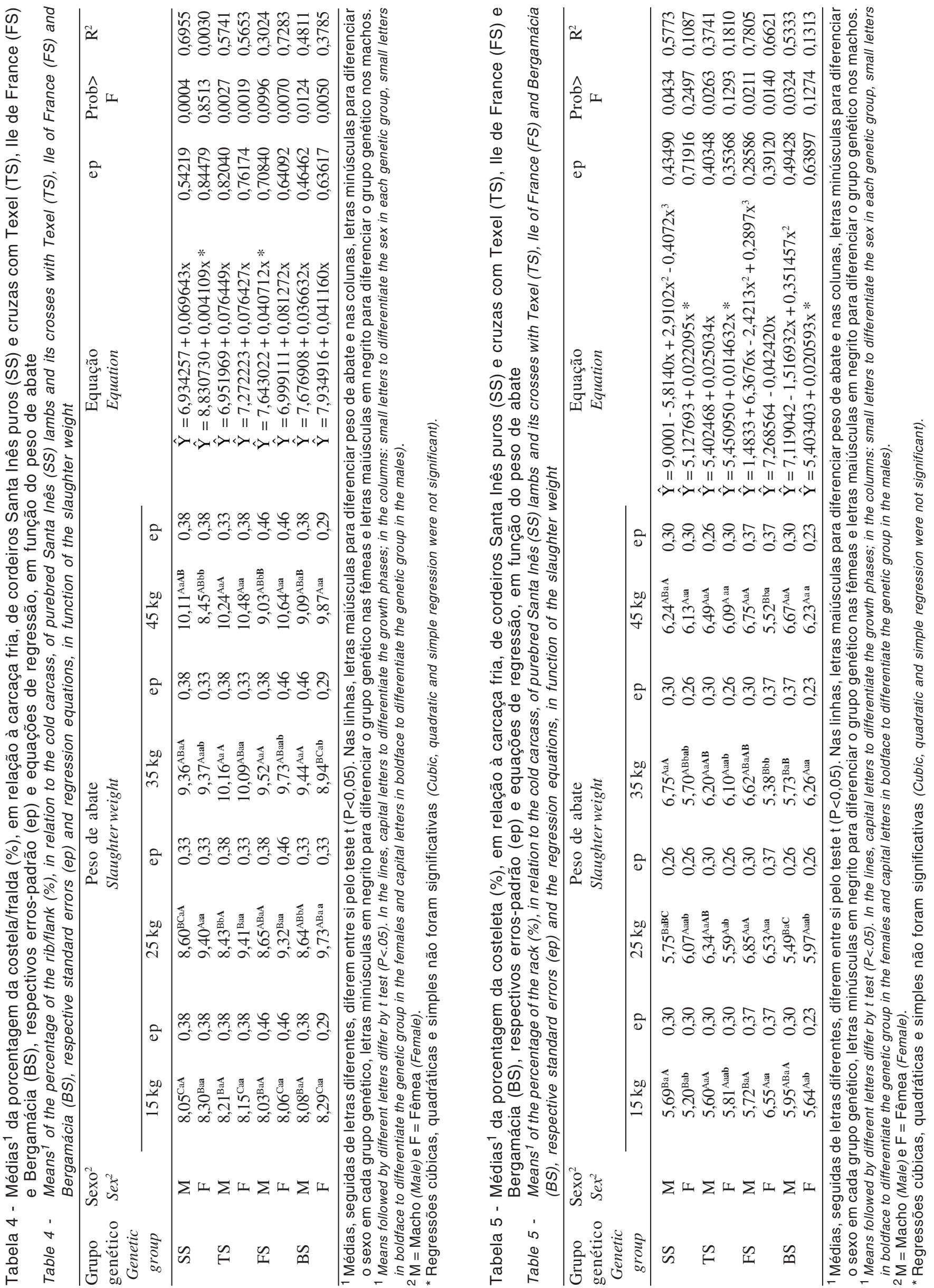

\section{R. Bras. Zootec., v.33, n.2, p.453-462, 2004}


fêmeas TS e as fêmeas BS mantiveram a proporção do corte em relação à carcaça fria semelhante nos quatro pesos de abate; as fêmeas FS apresentaram maior porcentagem no início.

Com relação aos dados de regressão, nota-se que, com o aumento do peso de abate, os animais machos TS apresentaram aumento linear $(\mathrm{P}<0,05)$ da proporção da costeleta. Já as fêmeas FS mostraram diminuição linear $(\mathrm{P}<0,05)$ dessa proporção. Para os outros grupos, o modelo linear não foi significativo $(\mathrm{P}<0,05)$. Os valores obtidos para os machos BS, nos diferentes pesos de abate, podem ser explicados por uma equação de regressão quadrática $(\mathrm{P}<0,05)$, indicando que a proporção foi maior no início e no final e menor em pesos intermediários. Para os machos SS e FS, a equação que melhor se ajustou foi a cúbica, indicando que a proporção deste corte varia muito de acordo com o peso de abate.

Na Tabela 6, são apresentados os valores médios para porcentagem do lombo em relação à carcaça fria.

Em todos os pesos de abate estudados, a proporção deste corte na carcaça fria foi a mesma entre machos e fêmeas, em todos os grupos genéticos. No entanto, Silva et al. (2000) verificaram que as fêmeas apresentaram lombos mais pesados do que os machos.

Nota-se que não houve diferença $(\mathrm{P}>0,05)$ entre os grupos genéticos quanto à porcentagem do lombo, com exceção das fêmeas abatidas aos $25 \mathrm{~kg}$, para as quais os dados mostram que as cordeiras FS tiveram maior proporção de lombo em comparação às fêmeas SS $(\mathrm{P}<0,05)$.

De maneira geral, os resultados obtidos para a porcentagem de lombo discordam do que é relatado por Kempster et al. (1987), os quais citaram que cordeiros filhos de pai Texel apresentaram maior porcentagem de lombo. No presente trabalho, praticamente não houve diferenças entre os grupos genéticos, mostrando que cordeiros puros Santa Inês podem apresentar proporções semelhantes de um corte importante comercialmente como o lombo.
Para os diferentes peso de abate, os machos SS, FS e BS mantiveram proporções semelhantes entre todos os pesos, enquanto os machos TS e as fêmeas de todos os grupos tiveram proporções menores aos $15 \mathrm{~kg}$, comparados aos animais abatidos aos $45 \mathrm{~kg}$.

De acordo com os dados de regressão, os machos e fêmeas SS e TS mostraram aumentos significativos $(\mathrm{P}<0,05)$ na proporção do lombo, com o aumento do peso de abate. Para os outros grupos genéticos e sexos em cada grupo, os modelos de regressão testados não foram significativos $(\mathrm{P}>0,05)$, indicando que praticamente não ocorreram variações na proporção de lombo com o aumento do peso. Os resultados citados por Silva \& Portugal (2000) mostraram aumentos na porcentagem do lombo em carcaças até $18 \mathrm{~kg}$.

Os dados referentes à porcentagem da perna na carcaça fria são apresentados na Tabela 7.

As porcentagens da perna foram semelhantes entre machos e fêmeas $(P>0,05)$. Em relação ao grupo genético, as cordeiras TS, aos $15 \mathrm{~kg}$, tiveram maior proporção que a das fêmeas BS $(\mathrm{P}<0,05)$. Aos $35 \mathrm{~kg}$, os machos TS apresentaram maior porcentagem da perna que os SS e BS abatidos no mesmo peso, ficando os cordeiros FS com proporção intermediária $(\mathrm{P}>0,05)$.

Aos 25 e $45 \mathrm{~kg}$, a porcentagem da perna foi semelhante entre todos os grupos genéticos $(\mathrm{P}>0,05)$. Analisando-se as médias entre os pesos de abate, verificou-se que a porcentagem da perna, obtida aos $15 \mathrm{~kg}$, foi maior que a obtida aos $45 \mathrm{~kg}(\mathrm{P}<0,05)$.

Conforme os dados da regressão, em todos os grupos genéticos foram verificadas diminuições $(\mathrm{P}<0,05)$ na porcentagem da perna e na carcaça fria, com o aumento do peso do animal, resultado semelhante ao encontrado por Bueno et al. (2000) e Silva \& Portugal (2000). De acordo com Lohose et al. (1971), Colomer \& Espejo (1973) e Osório et al. (1995), os quartos são de desenvolvimento precoce, ocasionando redução nas porcentagens desses cortes, quando ocorre aumento no peso da carcaça. 

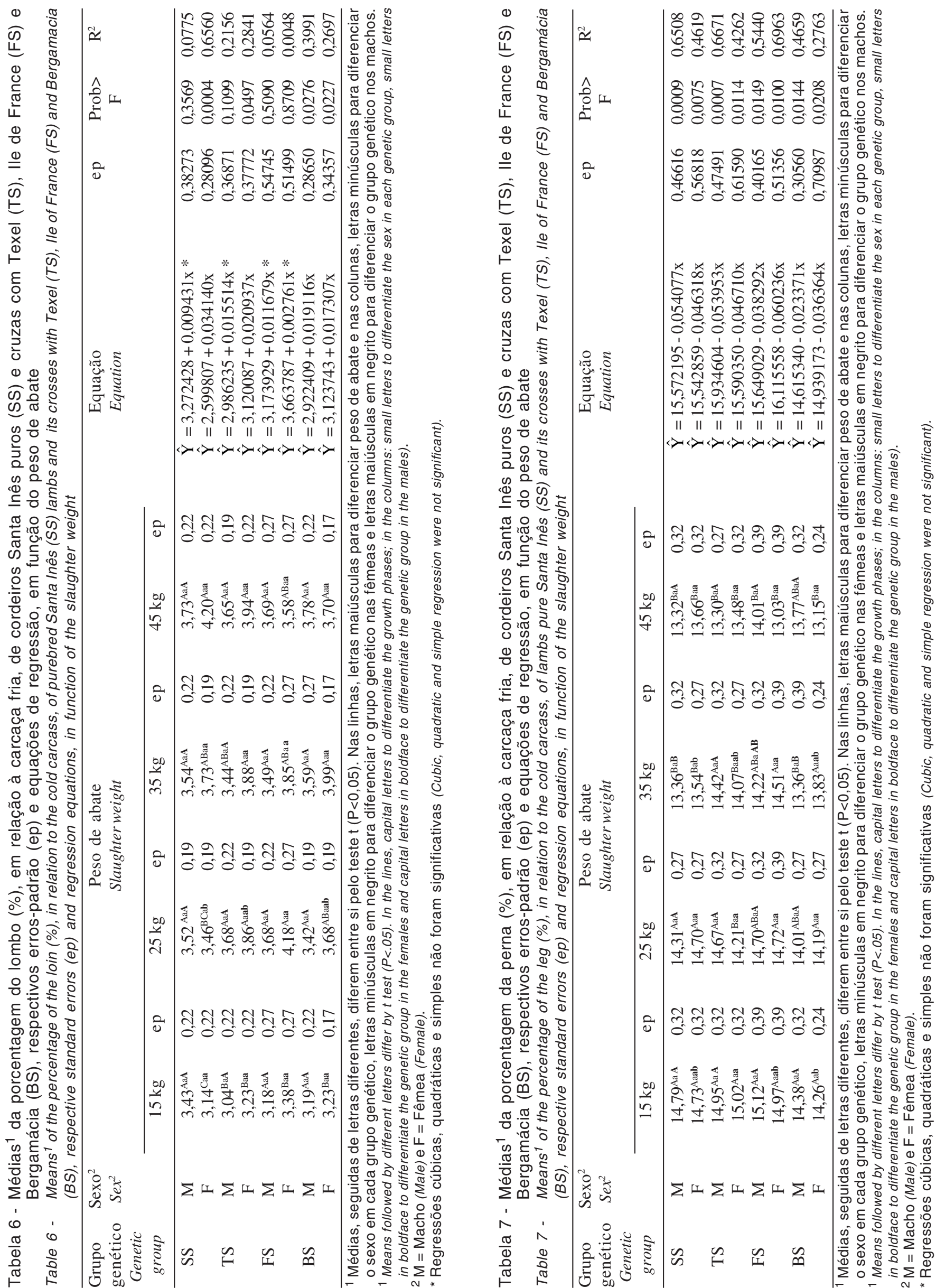

\section{R. Bras. Zootec., v.33, n.2, p.453-462, 2004}




\section{Conclusões}

As proporções de pescoço, paleta, costeleta e lombo praticamente não apresentaram alterações com o aumento do peso de abate.

A proporção da perna e da costela/fralda, em relação ao peso da carcaça fria, respectivamente, diminuiu e aumentou com o aumento de peso.

Os cordeiros cruzas Texel x Santa Inês e Ile de France x Santa Inês apresentaram menor porcentagem de pescoço e maiores proporções de paleta em relação aos cordeiros SS e BS, em pesos elevados.

Entre as fêmeas, as cordeiras FS apresentaram maiores proporções de perna aos $35 \mathrm{~kg}$; entre os machos, foram os cordeiros TS, abatidos aos $45 \mathrm{~kg}$.

\section{Literatura Citada}

AGRICULTURAL RESEARCH COUNCIL - ARC. The nutrient requeriment of farm animals. London: 1980. $351 \mathrm{p}$.

BUENO, M.S.; CUNHA, E.A.; SANTOS, L.E. et al. Características de carcaça de cordeiros Suffolk abatidos em diferentes idades. Revista Brasileira de Zootecnia, v.29, n.6, p.1803-1810, 2000.

COLOMER, F.; ESPEJO, M. Influencia del peso al sacrificio y del sexo sobre las características de las canales de cordero de raza Aragonesa. INIA, Serie Producción Animal, n.4, p.133-150, 1973.

COLOMER-ROCHER, F.; DELAT, R.; SIERRA-ALFRANCA,

I. Método normalizado para el estudio de los caracteres cuantitativos y cualitativos de las canales, según los sistemas de produccíon. In: Método normalizado para el estudio de los caracteres cuantitativos y cualitativos de las canales caprinas y ovinas. Cuad. INIA: 1988. v.17, p.19-41.

COLOMER-ROCHER, F.; DUMONT, B.L.; FERROL, N.L. Descrición del despiece ovino aragones e definicion de un despiece de referencia normalizado. Anales do Instituto Nacional de Investigaciones Agrarias, Serie Producción Animal, Madrid, n.3, 1972. Separata, n.8.

HUIDOBRO, F. R.; CAÑEQUE, V. Producción de carne en corderos de raza Manchega. II. Conformación y estado de engrasamiento de la canal y proporción de piezas en distintos tipos comerciales. Investigación Agraria. Producción y Sanidad Animal, v.8, n.3, p.233-243, 1993.

KEMPSTER, A.J.; CROSTON, D.; GUY, D.R. et al. Growth and carcass characteristics of crossbred lambs by tem sire breeds, compared at the same estimated carcass subcutaneus fat proportion. Animal Production, v.44, n.1, p.83-98, 1987.
LOHOSE, C.L.; MOSS, F.P.; BUTTERFIELD, R.M. Growth patterns of muscle of Merino sheep from birth to 517 days. Animal Production, v.13, n.1, p.117-126, 1971.

OLIVEIRA, N.M.; OSÓRIO, J.C.S.; MONTEIRO, E.M. Produção da carne de cinco genótipos. 4. Composição regional e tecidual. Ciência Rural, v.28, n.1, p.125-129, 1998.

OSÓRIO, J.C.S.; SIEWERDT, F.; OSÓRIO, M.T.M. et al. Desenvolvimento alométrico das regiões corporais em ovinos. Revista da Sociedade Brasileira de Zootecnia, v.24, n.2, p.326-333, 1995.

PERRY, D.; ARTHUR, P.F. Correlated responses in body composition and fat partitioning to divergent selection for yearling growth rate in Angus cattle. Livestock Production Science, v.62, n.2, p.143-153, Jan. 2000.

ROHR, K.; DAENICKE, R. Nutritional effects on the distribution of live weight as gastrointestinal tract fill and tissue components in growing cattle. Journal of Animal Science, v.58, n.3, p.753-765, 1984.

SAINZ, R.D. Qualidade das carcaças e da carne ovina e caprina. In: REUNIÃO ANUAL DA SOCIEDADE BRASILEIRA DE ZOOTECNIA, 33.; SIMPÓSIO INTERNACIONAL SOBRE TÓPICOS ESPECIAIS EM ZOOTECNIA, 1996, Fortaleza. Anais... Fortaleza, 1996. p.3-14.

SANTOS, C. L. Estudo do desempenho, das características da carcaça e do crescimento alométrico de cordeiros das raças Santa Inês e Bergamácia. Lavras: Universidade Federal de Lavras, 1999. 142p. Dissertação (Mestrado em Zootecnia) - Universidade Federal de Lavras, 1999.

SANTOS, C. L. dos; PEREZ, J. R. O. Composição dos cortes comerciais de cordeiros Santa Inês. In: ENCONTRO MINEIRO DE OVINOCULTURA, 1., 1998, Lavras. Anais... Lavras: Universidade Federal de Lavras, 2000. p.150-168.

STATISTICAL ANALYSES SYSTEM - SAS. SAS User's guide: Statistics. Version 8 (TS MO). Cary: 1999.

SILVA, L.F.; PIRES, C.C.; ZEPPENFELD, C.C. et al. Crescimento de regiões da carcaça de cordeiros abatidos com diferentes pesos. Ciência Rural, v.30, n.3, p.481-484, 2000.

SILVA, S.J.; PORTUGAL, A.V. The effect of weight on growth and carcass quality of Serra da Estrela and Merino Branco lambs raised in intensive production system. Revista Portuguesa de Zootecnia, v.7, n.1, p.109-129, 2000. 